\title{
Evaluation of the inner-retinal cells survival after low duration laser treatment measured by electroretinogram in patient with diabetic retinopathy
}

Arief S. Kartasasmita ${ }^{1,2^{*}}$, Ohisa Harley ${ }^{1,3}$, Irawati Irfani ${ }^{1,2}$ and Erwin Iskandar ${ }^{1,2}$

Correspondence: a.kartasasmita@unpad.ac.id

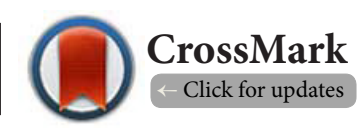

'Department Ophthalmology, Universitas Padjadjaran, Bandung, Indonesia.

${ }^{2}$ Cicendo National Eye Hospital, Bandung Indonesia.

${ }^{3}$ Netra Eye Hospital, Bandung Indonesia.

\begin{abstract}
Background and Objective: To evaluate the Inner-retinal cells survival after low duration laser treatment (50ms duration) measured by electroretinogram in patient with diabetic retinopathy

Methods: Twenty-two eyes with severe nonproliferative diabetic retinopathy or proliferative diabetic retinopathy that underwent three panretinal photocoagulation treatments were prospectively followed. The patients were divided into two groups involving the standard laser or low-duration laser treatment. Survival of the inner retina was assessed using a full-field electroretinography involving changes in amplitude and implicit times of the b-wave rod response.

Results: There was no significant change in amplitude in eyes treated with the low-duration laser $(-14.29 \pm 30.479 \mu \mathrm{V} ; \mathrm{p}=0.172)$, but there was a significant change in eyes treated with the standard laser $(-45.65 \pm 28.189 \mu \mathrm{V} ; \mathrm{p}=0.001)$. There was no significant change in implicit times in each group $(\mathrm{p}=0.177$ and $\mathrm{p}=0.685$, respectively). The change in amplitude in eyes treated with the low-duration laser was significantly lower than in eyes treated with the standard laser $(-71.43 \pm 25.408$ versus $8.18 \pm 86.432$, respectively; $\mathrm{p}=0.018$ ).
\end{abstract}

Conclusions: Treatment with the low-duration laser is effective in maintaining the survival of inner retinal cells.

Keywords: Low duration Laser, Inner Retina Survival, Diabetic Retinopathy

\section{Introduction}

Diabetic retinopathy (DR) is the leading cause of blindness due to the ischemic condition of the disease. Numerous studies have reported that growth factors are the most important factors for the progression of DR leading to neovascularization. Vascular endothelial growth factor (VEGF) is considered the most important initiating factor responsible for severe complications due to proliferative diabetic retinopathy (PDR) of the inner retinal layers. The incidence of blindness due to DR varies from $6.8-44.4 \%$, and is increasing both in developed and developing countries [1-3].

Panretinal photocoagulation (PRP) is still the main standard of treatment for PDR [4]. This treatment destroys some of the photoreceptors to reduce the oxygen demand in the outer layers of the retina. The retinal pigment epithelium (RPE) absorbs the laser radiation and transforms it into heat to destroy the surrounding cells, especially the photoreceptors located above the RPE. By destroying some of the photoreceptors, oxygen from the choriocapillaris passes through the outer retina and goes directly to the inner retina to restabilize the oxygen supply and demand. It is therefore reasonable to assume that the objective of PRP is to increase the oxygen supply to the inner retina to decrease the ischemic condition by destroying some of the photoreceptors [5].

Unfortunately, heat from photocoagulation frequently not only destroys photoreceptors but also affects other surround- 
ing cells, including the inner retinal cells [6]. Many patients therefore still experience reduced visual acuity and peripheral visual field defects. It is known that $>95 \%$ of the photoreceptors are rod cells. After phototransduction, they collect the signals and transmit them to the inner retinal cells before they are transmitted to nerve fibers. Approximately 20-100 rods converge to a single bipolar cell, and approximately $100 \mathrm{rod}$ bipolar cells converge to a ganglion cell [7]. By preserving the inner retinal layers, signals from unaffected photoreceptors can still be transmitted to bipolar and other inner retinal cells to reduce the side effects of laser treatment. In the present study, we therefore evaluated the efficacy of low-duration laser treatment $(50 \mathrm{~ms})$ in preserving the survival of inner retinal cells in patients with DR.

\section{Patients and methods}

This study was conducted from 2014 to 2015, adhered to the tenets of the Declaration of Helsinki, and was approved by the Institutional Review Board at the University of Padjajaran. Inclusion criteria included patients $\geq 18$ years of age with proliferative diabetic retinopathy (PDR) or severe nonproliferative diabetic retinopathy (severe NPDR) planned PRP, with the ability to comply with testing and follow-ups. Exclusion criteria included patients with significant media opacities and with a history of intraocular laser treatment or surgery. Written informed consent that adhered to good clinical practice regulations was obtained from each patient.

Ophthalmic examinations at baseline and 1 week after treatment included ETDRS best-corrected visual acuity (BCVA); measurement of intraocular pressure (IOP); slit-lamp biomicroscopy, indirect ophthalmoscopy; and a full-field electroretinography (ERG) examination. Fulfield erg was done using Roland ERG (Roland Electrophysiological Instrument, Essen Germany) based on ISCEV standard with rod respons using stimulative strength weaker than 2.5 logunit. All the patient had 20 minutes dark adaptation prior of rod response stimulation. Scotopic ff ERG was interpreted by implicit time and amplitude of $\mathrm{b}$ wave in rod response with normal criterion of implicit time $60-80 \mathrm{~ms}$ and amplitude 175-471 micronvolt.

PRP was performed in three sessions at 1-week intervals using an argon laser with slit-lamp biomicroscopy (Carl Zeiss Meditec, Jena, Germany) with an OMRA-PRP 165 (US Ophthalmic, Doral, FL, USA) ocular contact lens. The PRP technique was perform as describe elsewhere [8]. Patients were randomized by permutated blocks and divided into two groups that were treated with a standard laser or a low-duration laser. The standard laser treatment according to ETDRS was performed using a 100-ms pulse duration and a 300-500- $\mu \mathrm{m}$ spot with adjusted laser power to produce a grade 2-3 laser burn. The low-duration laser involved a 50-ms pulse and 300-500- $\mathrm{mm}$ spot with adjusted laser power to produce a grade 2 laser burn.

A paired $t$-test was used to generate $p$-values, and a value $<0.05$ was considered significant. Statistical analyses were performed using the SPSS statistical software for Windows, version 16.0 (SPSS, Chicago, IL, USA).

\section{Results}

A total of 22 eyes of patients with severe NPDR or PDR were included. The patient ages ranged from 43-68 years of age (mean, 49.40 \pm 7.412 years) in group A (standard laser) and 5168 years of age (mean, $55.50 \pm 5.442$ ) in group B (low-duration laser). Patient demographics and baseline characteristics are summarized in Table 1.

Eyes in the standard laser group received an average of $1,680.10$ shots with an average power of $170.33 \mathrm{~mW}$, and eyes in the low-duration laser group received $2,157.40$ shots with an average power of $259.67 \mathrm{~mW}$ as shown in Table 2 .

The changes in amplitude and implicit times are shown in Tables 3-5, where significant comparisons are designated with appropriate $p$-values.

Table 1. Demographic and Clinical Characteristics of The Patients.

\begin{tabular}{llll}
\hline Characteristic & Group A & Group B & P value \\
\cline { 2 - 3 } & $\mathbf{n = 1 0}$ & $\mathbf{n}=\mathbf{1 0}$ & \\
\hline Age (years) & & & \\
\hline Mean \pm SD & $49.40 \pm 7.412$ & $55.50 \pm 5.442$ & 0.0503 \\
Range & $43-68$ & $51-68$ & -- \\
\hline Diagnose (\%) & & & \\
\hline Severe NPDR & $2(20 \%)$ & $4(40 \%)$ & 0.628 \\
PDR & $8(80 \%)$ & $6(60 \%)$ & -- \\
\hline
\end{tabular}

Table 2. The Average PRP Setting in Group A and Group B.

\begin{tabular}{llll}
\hline Setting & Group A & Group B & \multirow{2}{*}{ P value } \\
\cline { 2 - 3 } & $(\mathbf{n = 1 0 )}$ & $\mathbf{( n = 1 0 )}$ & \\
\hline Pulse Duration (ms) & 100 & 50 & \\
Power (mW) & $170.33 \pm 21.855$ & $259.67 \pm 56.578$ & $0.001^{*}$ \\
Number of Shots & $1680.10 \pm 232.132$ & $2157.40 \pm 465.796$ & $0.010^{*}$ \\
\hline
\end{tabular}

Table 3. Comparison of The Amplitude in Rod Response between Pre- and Post laser.

\begin{tabular}{lll}
\hline Amplitude & Group A $(\mathbf{n}=\mathbf{1 0})$ & Group B $(\mathbf{n = 1 0})$ \\
\hline Prelaser & $61.59 \pm 29.873$ & $61.59 \pm 29.873$ \\
Postlaser & $15.97 \pm 17.587$ & $12.86 \pm 12.388$ \\
Difference & $-45.65 \pm 28.189$ & $-14.29 \pm 30.479$ \\
P value & $0.001^{*}$ & 0.172 \\
\hline
\end{tabular}

Table 4. Comparison of The Implicit Time in Rod Response between Pre- and Post laser.

\begin{tabular}{lll}
\hline ImplicitTime & Group A $(\mathbf{n}=\mathbf{1 0})$ & Group B (n=10) \\
\hline Prelaser & $87.60 \pm 14.431$ & $62.00 \pm 37.974$ \\
Postlaser & $69.95 \pm 32.842$ & $57.30 \pm 32.442$ \\
Difference & $-17.66 \pm 38.080$ & $-4.70 \pm 35.425$ \\
P value & 0.177 & 0.685 \\
\hline
\end{tabular}


There was a significant difference in amplitude between preand post-laser eyes in group $\mathrm{A}(-45.65 \pm 28.189 \mu \mathrm{V} ; \mathrm{p}=0.001)$. There was no significant difference in group $B(-14.29 \pm 30.479$ $\mu \mathrm{V} ; \mathrm{p}=0.172$ ).

After therapy, there was no significant difference in the implicit time in each group $(p=0.177$ and $p=0.685$, respectively; Table 4).

Table 5 shows significant differences in amplitude changes between the two groups $(-71.43 \pm 25.408$ versus $8.18 \pm 86.432$; $\mathrm{p}=0.018$ ), but no significant difference in amplitude change in implicit times between the two groups $(-15.21 \pm 51.208$ versus $17.04 \pm 82.808 ; p=0.309$ ).

Table 5. Comparison of Change in Amplitude and Implicit Time between Two Groups.

\begin{tabular}{llll}
\hline & $\begin{array}{l}\text { Group A } \\
(\mathbf{n}=\mathbf{1 0})\end{array}$ & $\begin{array}{l}\text { Group B } \\
(\mathbf{n = 1 0})\end{array}$ & P value \\
\hline Change in Amplitude (\%) & $-71.43 \pm 25.408$ & $8.18 \pm 86.432$ & $0.018^{*}$ \\
$\begin{array}{l}\text { Change in Implicit time } \\
(\%)\end{array}$ & $-15.21 \pm 51.208$ & $17.04 \pm 82.808$ & 0.309 \\
\hline
\end{tabular}

\section{Discussion}

The results in the present study provide a better understanding of the laser effects on inner retinal cells. Because of their potential importance, we focused on the rod response and followed its changes during treatment. The inner retina can only be quantitatively assessed using an ERG examination. The b-waves reflect signal transmission from the photoreceptors to the inner retinal cells. The amplitude of the b-wave may decrease if there are conditions that affect this transmission. Previous studies analyzing the effects of standard (ETDRS) laser treatment of retinal cells have reported varying results. Gjotterberg et al. reported more damage to photoreceptors than to inner retinal cells. Perlman et al. reported the same relative damage to all layers, but Liang et al. reported more damage to inner retinal cells [9-11].

Our study showed a significant difference in decreased amplitude $(p=0.046)$ between the eyes treated with the standard laser versus eyes treated with the low-duration laser. The amplitude of b-waves decreased by $45.65 \%$ in the standard laser group, and $14.29 \%$ in the low-duration laser group. Lafond et al. also reported that standard (ETDRS) laser treatment resulted in a $71 \%$ decrease in the amplitude of b-waves [12]. It is possible that the laser caused significant damage to the photoreceptors and to other cells in the inner retinal layers, thus resulting in lower transmitted signals and decreased amplitude. Taken together, the present study showed that a standard laser caused more damaged to inner retinal cells than a low-duration laser.

There were two eyes in the low-duration group with a greater decrease in amplitude than the other eyes. Although the exact reason was still unclear, it is possible that ischemia in the peripheral retina was still progressing. Unlike vitrectomy, the laser could not reach the anterior of the oraserrata. An ischemic process in this area was assumed to affect the rod responses using ERG, because this examination calculates the summation of electrical responses in all of the peripheral retina. Fundus photo angiography is known to be an appropriate method to evaluate ischemic areas. However, the decreased amplitude of the rod response after standard laser treatment was significantly higher after the low-duration laser treatment.

As previously mentioned, the objective of PRP is to restabilize the oxygen supply and consumption [13]. Laser treatment destroys some of the photoreceptors and other surrounding cells, and cells damaged by ischemia can no longer consume oxygen [14]. However, oxygen consumption can be performed by other healthy retinal cells. The restabilized oxygenation in the retina provides a good environment for repair of retinal tissue, so it is possible that tissue repairing can compensate for the damage resulting from laser treatment.

In addition to evaluating the effects of laser treatment, we also determined the delay of the implicit time, which is the time required to reach the peak of the wave, measured from the beginning of the stimulus to the peak of the wave [15]. In contrast to a decreased amplitude, our analyses showed no significant difference in the change of implicit times between the two groups $(p=0.309)$. A possible explanation involves successful oxygenation in the retina after laser treatment, especially in the inner retinal layers. Repair of the tissue occurred in 3 days after laser treatment [16]. The ERG examination that was performed a week after the last (third) session of PRP might therefore show improvement of electrical signals.

The post-laser implicit times improved in several eyes. The destruction to damaged photoreceptors succeeded in restoring tissue oxygenation, providing an opportunity for the undestroyed photoreceptors to optimize their functions. However, in other eyes, we also found a delayed implicit time compared with pre-laser levels, which could be caused by continued ischemia and by the damaged retinal tissue.

Our results suggest that in clinical practice, use of the lowduration laser might result in decreased inner retinal damage. A low-duration laser provides for retinal tissue repair. In the present study, two patients were excluded because they did not complete the procedures according to the protocol. However, the post-laser ERG examination 2 months after the last session of PRP was still performed. In contrast to the other results, there was a surprising increase of amplitude. A possible explanation was the restoration of retinal structure and its function, which has been postulated to occur 8 weeks after laser treatment. Sher et al. suggested that retinal restoration could occur by retention of old synapses, the origination of new synapses, or both [6].

The limitation of this study was the short follow-up time: only 1 week after the last PRP treatment. However, we postulate that damage to the photoreceptors is most prevalent during this period, and the rod response in the ERG examination should provide the expected results. The small number of patients might also be a limitation of this study, so additional studies 
with larger numbers of patients are necessary.

In conclusion, the low-duration laser maintains the survival of inner retinal cells. These results, if confirmed by a larger sample size and longer follow-ups, may result in better treatment for patients with a retinal ischemic disease, especially those with DR.

\section{Competing interests}

The authors declare that they have no competing interests.

\section{Authors' contributions}

\begin{tabular}{|l|c|c|c|c|}
\hline Authors' contributions & ASK & OH & II & EI \\
\hline Research concept and design & $\checkmark$ & $\checkmark$ & $\checkmark$ & $\checkmark$ \\
\hline Collection and/or assembly of data & -- & $\checkmark$ & $\checkmark$ & -- \\
\hline Data analysis and interpretation & $\checkmark$ & $\checkmark$ & $\checkmark$ & $\checkmark$ \\
\hline Writing the article & $\checkmark$ & $\checkmark$ & $\checkmark$ & -- \\
\hline Critical revision of the article & $\checkmark$ & $\checkmark$ & -- & $\checkmark$ \\
\hline Final approval of article & $\checkmark$ & $\checkmark$ & -- & -- \\
\hline Statistical analysis & $\checkmark$ & $\checkmark$ & -- & $\checkmark$ \\
\hline
\end{tabular}

\section{Acknowledgments}

The authors hereby acknowledge the supports of Universitas Padjadjaran Research Internal Grant.

Publication history

Editor: Reas Khan Sulaimankutty, University of Pennsylvania, USA. Received: 23-Jun-2017 Final Revised: 24-Aug-2017

Accepted: 05-Sep-2017 Published: 09-Sep-2017

\section{References}

1. Zheng $\mathrm{Y}$, Lamoureux EL, Lavanya R, Wu R, Ikram MK, Wang JJ, Mitchell $P$, Cheung N, Aung T, Saw SM and Wong TY. Prevalence and risk factors of diabetic retinopathy in migrant Indians in an urbanized society in Asia: the Singapore Indian eye study. Ophthalmology. 2012; 119:2119-24. | Article | PubMed

2. Klein BE. Overview of epidemiologic studies of diabetic retinopathy. Ophthalmic Epidemiol. 2007; 14:179-83. | Article | PubMed

3. Rema M, Premkumar S, Anitha B, Deepa R, Pradeepa R and Mohan V. Prevalence of diabetic retinopathy in urban India: the Chennai Urban Rural Epidemiology Study (CURES) eye study, I. Invest Ophthalmol Vis Sci. 2005; 46:2328-33. | Article | PubMed

4. Early photocoagulation for diabetic retinopathy. ETDRS report number 9. Early Treatment Diabetic Retinopathy Study Research Group. Ophthalmology. 1991; 98:766-85. | Article | PubMed

5. Stefánsson E. The Mechanism of Retinal Photocoagulation - How Does the Laser Work? European Ophthalmic Review. 2009; 2:3.

6. Sher A, Jones BW, Huie P, Paulus YM, Lavinsky D, Leung LS, Nomoto $H$, Beier C, Marc RE and Palanker D. Restoration of retinal structure and function after selective photocoagulation. J Neurosci. 2013; 33:6800-8. I Article | PubMed Abstract | PubMed FullText

7. Volgyi B, Deans MR, Paul DL and Bloomfield SA. Convergence and segregation of the multiple rod pathways in mammalian retina. $J$ Neurosci. 2004; 24:11182-92. | Article | PubMed Abstract | PubMed FullText

8. Dowler JG. Laser management of diabetic retinopathy. $J R$ Soc Med. 2003; 96:277-9. | PubMed Abstract | PubMed FullText

9. Perlman I, Gdal-On M, Miller B and Zonis S. Retinal function of the diabetic retina after argon laser photocoagulation assessed electroretinographically. Br J Ophthalmol. 1985; 69:240-6. | Article | PubMed Abstract I PubMed FullText

10. Liang JC, Fishman GA, Huamonte FU and Anderson RJ. Comparative electroretinograms in argon laser and xenon arc panretinal photocoagulation. Br J Ophthalmol. 1983; 67:520-5. | Article | PubMed Abstract | PubMed FullText

11. Gjötterberg $M$ and Blomdahl S. Human Electroretinogram after Argon Laser Photocoagulation of Different Retinal Areas. Ophthalmic Research. 1981; 13:42-49. | Article

12. Lafond G, Boucher MC, Labelle P and Dumas J. The Effects of Laser Panretinal Photocoagulation on Cone, Rod and Oscillatory Potentials Responses in Proliferative Diabetic Retinopathy. Investigative Ophthalmology \& Visual Science. 2003; 44:3986-3986. | Article

13. Stefansson E, Landers MB, 3rd and Wolbarsht ML. Increased retinal oxygen supply following pan-retinal photocoagulation and vitrectomy and lensectomy. Trans Am Ophthalmol Soc. 1981; 79:307-34. | PubMed Abstract I PubMed FullText

14. Yu DY, Cringle SJ, Su E, Yu PK, Humayun MS and Dorin G. Laser-induced changes in intraretinal oxygen distribution in pigmented rabbits. Invest Ophthalmol Vis Sci. 2005; 46:988-99. | Article | PubMed

15. Fujiwara E, Qiu H, Liu M, Lam BL, Parel JM, Inana G and Hamasaki DI. Reliability and significance of measurements of a-wave latency in rats. Jpn J Ophthalmol. 2002; 46:419-25. | PubMed

16. Romero-Aroca P, Reyes-Torres J, Baget-Bernaldiz M and Blasco-Sune C. Laser treatment for diabetic macular edema in the 21st century. Curr Diabetes Rev. 2014; 10:100-12. | Article | PubMed Abstract | PubMed FullText

\section{Citation:}

Kartasasmita AS, Harley O, Irfani I and Iskandar E. Evaluation of the inner-retinal cells survival after low duration laser treatment measured by electroretinogram in patient with diabetic retinopathy. J Eye Ophthalmol. 2017; 4:2.

http://dx.doi.org/10.7243/2055-2408-4-2 